\title{
Collectin-11 Is an Important Modulator of Retinal Pigment Epithelial Cell Phagocytosis and Cytokine Production
}

\author{
Xia Donga, ${ }^{a}$ Weiju Wu ${ }^{b}$ Liang Ma ${ }^{b}$ Chengfei Liu ${ }^{c}$ Mohajeet B. Bhuckory ${ }^{d}$ \\ Liping Wang ${ }^{a}$ Emeline F. Nandrot ${ }^{e}$ Heping Xu $^{d} \mathrm{Ke} \mathrm{Li}^{\mathrm{c}}$ Yizhi Liu $^{\mathrm{a}}$ \\ Wuding Zhou ${ }^{\mathrm{b}}$ \\ a State Key Laboratory of Ophthalmology, Zhongshan Ophthalmic Center, Sun Yat-sen University, Guangzhou, \\ China; ${ }^{b}$ Medical Research Council (MRC) Centre for Transplantation, King's College London, Guy's Hospital, London, \\ UK; ' C Core Research Laboratory, the Second Affiliated Hospital, School of Medicine, Xi'an Jiaotong University, Xi'an, \\ China; ${ }^{\mathrm{d} C e n t r e}$ for Experimental Medicine, Queen's University Belfast, Belfast, UK; ${ }^{\mathrm{e}}$ Department of Therapeutics, \\ INSERM U968, UPMC Université Paris 06 UMR S968, Institut de la Vision, CNRS UMR 7210, Paris, France
}

\section{Keywords}

Collectin $11 \cdot \mathrm{CL}-\mathrm{K} 1 \cdot$ Opsonophagocytosis · Cytokine production $\cdot$ Retinal pigment epithelial cells

\begin{abstract}
In this paper, we report previously unknown roles for collectin-11 (CL-11, a soluble C-type lectin) in modulating the retinal pigment epithelial (RPE) cell functions of phagocytosis and cytokine production. We found that CL-11 and its carbohydrate ligand are expressed in both the murine and human neural retina; these resemble each other in terms of RPE and photoreceptor cells. Functional analysis of murine RPE cells showed that CL-11 facilitates the opsonophagocytosis of photoreceptor outer segments and apoptotic cells, and also upregulates IL-10 production. Mechanistic analysis revealed that calreticulin on the RPE cells is required for CL-11-mediated opsonophagocytosis whereas signal-regulatory protein a and mannosyl residues on the cells are involved in the CL-11-mediated upregulation of IL-10 production. This study
\end{abstract}

Xia Dong and Weiju Wu contributed equally to this work. is the first to demonstrate the role of $\mathrm{CL}-11$ and the molecular mechanisms involved in modulating RPE cell phagocytosis and cytokine production. It provides a new insight into retinal health and disease and has implications for other phagocytic cells.

(c) 2017 S. Karger AG, Basel

\section{Introduction}

The retinal pigment epithelium (RPE) is a monolayer of pigmented epithelial cells situated between the photoreceptors and the choroid. It has multiple functions, including phagocytosis, secretion, visual cycle, glial support, epithelial transport, and light absorption [1]. In the retina, the outer segments of both the rods and cones of photoreceptor cells (PRC) are dynamic structures that undergo constant renewal. This process consists of the synthesis of new outer-segment disks by PRC, the shedding of the most distal tip of the outer segments, and the removal of the shedded outer segments by the RPE cells. The process is vital for the maintenance of photorecep-

Prof. Wuding Zhou

MRC Centre for Transplantation, King's College London

5th Floor Tower Wing, Guy's Hospital

Great Maze Pond, London SE1 9RT (UK)

E-Mail wuding.zhou@kcl.ac.uk 
tors and vision [2]. RPE cells are among the most active phagocytic cells in the body, thus playing a critical role in the removal of shedded photoreceptor outer segments (POS) by phagocytosis and degradation [3]. RPE cells can produce a number of cytokines and growth factors which are thought to be able to modulate a wide variety of cellular responses, thus participating in the maintenance of immune homeostasis in the retina as well as contributing to the pathogenesis of retinopathy. The molecular mechanisms in the regulation of RPE cell phagocytosis and cytokine production are yet to be fully understood. Identifying the key mediators of modulating RPE phagocytosis and cytokine production will improve our understanding of the homeostasis of the retinal microenvironment and the pathogenesis of retinopathy. Collectins are soluble C-type lectins and a part of the innate immune system; so far, 6 types of collectins have been defined [4-7]. Collectins are pattern-recognition proteins composed structurally of a carbohydrate-recognition domain (CRD), a neck region, and a collagen-like region, and are involved in carbohydrate recognition and innate immunity $[8,9]$. Well-known collectins include the mannan-binding lectin (MBL) and lung surfactant proteins (SP-A and SP-D). Collectins can bind to a variety of carbohydrate structures, mannose-rich glycans, and the surface of microorganisms to mediate innate immune responses to pathogens or tissue injury, such as triggering complement activation [10], opsonizing pathogens or apoptotic cells [11], facilitating macrophage phagocytosis [12], and modulating inflammatory responses [12]. Collectin-11 (CL-11, also known as CL-K1 and encoded by COLEC11) is, like CL-L1 (liver) and CL-P (placenta), a newly described member of the collectin family of proteins, which has a structure similar to MBL, SP-A, and SP-D, consisting of a CRD, followed by a neck region, and a collagen-like region. CL-11 is highly conserved across species, e.g., humans and mice share $92 \%$ similarities at the amino acid level. CL-11 has a wide tissue distribution; high-level expression has been found in the kidneys, liver, and adrenal glands $[13,14]$. It has been shown to bind to various molecules/molecular patterns through its CRD (e.g., monosaccharides, LPS, DNA, apoptotic cells, microorganisms, and the stress-induced L-fucose pattern on renal tubules) $[6,13,15,16]$. It has also been suggested that it plays an important role in host defense, waste removal, and embryonic development $[6,17,18]$, as well as participating in the pathogenesis of renal ischemia/reperfusion injury [15]. Given the important role of collectins in the opsonization and modulation of inflammatory responses, we hypothesized that CL-11 and, more specifically, locally produced CL-11, may play an important role in removing shedded POS by RPE cells and maintaining the homeostasis of the retinal microenvironment. To test this, we examined whether CL-11 and, possibly, carbohydrate ligands are produced in the murine and human retina, and investigated whether and how CL-11 modulates RPE cell phagocytosis and cytokine production.

\section{Materials and Methods}

\section{Materials}

We used goat polyclonal anti-human CL-11 antibody (sc242497, Santa Cruz, CA, USA); donkey anti-goat Alexa Fluor 568, goat anti-rabbit Alexa Fluor 568, donkey anti-rabbit Alexa Fluor 488, goat anti-rabbit Alexa Fluor 488, garamycin, kanamycin, a-mannosidase, galactosidase, and trypsin-EDTA testicular hyaluronidase (Sigma, Dorset, UK); rabbit polyclonal anti-mouse ZO-1 antibody (Invitrogen, Loughborough, UK); rabbit polyclonal anti-mouse signal-regulatory protein a (SIRPa) (C-Term) antibody (Antibodies-online, Germany); rabbit polyclonal antimouse calreticulin antibody, SIRPa-blocking antibody (rat antiSIRPa monoclonal) and rat IgG1 $\kappa$ (Abcam, Cambridge, UK); calreticulin-blocking antibody (rabbit polyclonal) (Novus Europe, Abingdon, UK); rabbit polyclonal anti-human CL-11 (abx003772, Abbexa Ltd., Cambridge, UK); donkey anti-rabbit Alexa Fluor 594 (Biolegend, London, UK); rabbit polyclonal anti-human C3d (DAKO, Glostrup, Denmark); fluorescein-labeled Galanthus nivalis lectin (GNL), Lens culinaris agglutinin (LCA), Lotus tetragonolobus lectin (LTL), and Ulex europaeus I (UEA-I) (Vector Laboratories, Peterborough, UK); 4',6-diamidino-2-phenylindole (DAPI) (Life Sciences, Paisley, UK); recombinant mouse CL-11 (Stratech Scientific, Newmarket, UK); ELISA kits for mouse IL-6 (555240) and IL-10 (555252) (BD Biosciences, San José, CA, USA); cell culture medium (RPMI 1640 and DMEM/F12), fetal calf serum (FCS) (Invitrogen); donkey anti-goat Alexa Fluor 488 IgG (Jackson ImmunoResearch Lab., West Grove, PA, USA); FcRblocking antibody (CD16/32, 2.4G2; BD Biosciences Pharmingen, San Diego, CA, USA); collagenase type II (Worthington Biochemical Corp., Lakewood, NJ, USA); Alexa 488 phalloidin, Alexa 568 phalloidin, and heat-inactivated normal sera (from donkey, goat, and rabbit), TRIzol reagent, Oligo(dT) 12-18 primer (Thermo Fisher Scientific, Paisley, UK); 5(6)-TAMRA SE (mixed isomers; Molecular Probes, Cambridge, UK); and the RT-PCR reagents (nucleotide mixture, recombinant RNasin ribonuclease inhibitor, M-MLV reverse transcriptase, GoTaq G2 Green master mix) (Promega, Southampton, UK).

Mice

Wild-type (WT) and knockout (KO) mice with deficiencies of CL-11 were on a C57BL/6 background. Homozygous Colec11 KO $\left(\mathrm{CL}-11^{-/-}\right)$mice were purchased from Mutant Mouse Resource and Research Centers (UC Davis, Davis, CA, USA) [19]. All mice were maintained in specific pathogen-free conditions.

Cell Culture

For the primary RPE cell culture, cells were prepared from mouse eyes according to previously described protocols [20]. In 
brief, mice were killed 8-18 days after birth. Their eyes were nucleated and rinsed 3 times in sterile PBS containing $50 \mu \mathrm{g} / \mathrm{mL}$ of garamycin and $100 \mu \mathrm{g} / \mathrm{mL}$ of kanamycin. Intact eyes were incubated consecutively at $37^{\circ} \mathrm{C}$ in 2 enzyme solutions. The first incubation was in PBS containing $105 \mathrm{U} / \mathrm{mL}$ of collagenase and $50 \mathrm{U} / \mathrm{mL}$ of testicular hyaluronidase ( $1 \mathrm{~mL} /$ eye) for $45-90 \mathrm{~min}$. The second incubation was in PBS containing $0.1 \%$ trypsin ( $1 \mathrm{~mL} /$ eye) for 60 min. Eyes were agitated every 10 min during incubation in the enzyme solutions. After incubation, they were placed in growth medium consisting of $20 \%$ FCS, followed by microdissection, i.e., eyes were opened by an incision just below the ora serrata, and the anterior segment and vitreous were discarded. The retina was gently lifted off the eyecup and the RPE was peeled off from both the retina and choroid. The isolated RPE was placed in fresh medium, and transferred to a conical $15-\mathrm{mL}$ centrifuge tube. RPE tissue was rinsed 3 times with PBS and incubated in $1 \mathrm{~mL}$ of $0.1 \%$ trypsin in $\mathrm{PBS}$ at $37^{\circ} \mathrm{C}$ for $3-5 \mathrm{~min}$ and followed by gentle pipetting to dissociate the RPE tissue into a single-cell suspension. The activity of trypsin was then stopped by adding 3-4 $\mathrm{mL}$ of culture medium. The cell suspension was centrifuged at 1,000 rpm for $2 \mathrm{~min}$, and the pellets were collected and resuspended in culture medium (DMEM/F-12 medium containing 20\% FCS and 1\% antibiotics; $0.5 \mathrm{~mL}$ of growth medium for every $8-10$ eyes). The RPE cells were kept at $37^{\circ} \mathrm{C}$ in an incubator. Culture medium was changed every $2-3$ days until the cells reached $80 \%$ confluency and were ready for experiments. For the RPE cell-line culture, the RPE cell line (B6$\mathrm{RPE} 07$ ) arose spontaneously and was cloned from a primary culture of mouse RPE cells, with a morphology, phenotype, and function similar to those of in vivo mouse RPE cells. Cells were wellmaintained in DMEM/F-12 medium containing 10\% FCS [21].

\section{Tissue Preparation}

For eye tissue, mouse or human eyes were fixed in $4 \%$ paraformaldehyde (PFA) in PBS for $4 \mathrm{~h}$, followed by a cryoprotection process in $10 \%$ and $30 \%$ sucrose. They were then mounted in OCT embedding compound and frozen at $-80^{\circ} \mathrm{C}$. Sections, about $4-\mu \mathrm{m}-$ thick, were used for immunohistochemistry and lectin staining. Human eyes were obtained from the Eye Bank of Guangdong Province. For the flat mount of RPE-choroid complex, the connective tissue, muscle, and optic nerve were removed from the back of the mouse eye. The cornea and lens were removed along the ora serrata. Next, several cuts were made along the radial axis of the remaining tissues, to make them flat. Finally, the neural retina was gently lifted off, revealing an intact RPE which was still attached to the underlying choroid and sclera. The flat mount of RPE-choroid complex was fixed in $4 \%$ PFA at $4{ }^{\circ} \mathrm{C}$ for $30 \mathrm{~min}$, and this was used for immunohistochemistry.

\section{Immunohistochemistry}

For the detection of CL-11 and calreticulin in the mouse eye, cryosections of eyes or flat-mount of RPE-choroid complex were incubated with anti-mouse CD16/32 for $30 \mathrm{~min}$ on ice, and then incubated with primary antibodies including goat anti-mouse CL11 and rabbit anti-mouse calreticulin at $4{ }^{\circ} \mathrm{C}$ overnight, followed by incubation with fluorophore-conjugated secondary antibodies (donkey anti-goat Alexa Fluor 568 and goat anti-rabbit Alexa Fluor 568) for $1 \mathrm{~h}$ at room temperature. For the detection of CL-11 in the human eye, cryosections were incubated with $10 \%$ normal donkey serum for $30 \mathrm{~min}$, with primary rabbit anti-human CL-11 at $4{ }^{\circ} \mathrm{C}$ overnight, and then with donkey anti-rabbit Alexa Fluor
594 for $1 \mathrm{~h}$ at room temperature. Nuclear counterstaining was performed using DAPI. In some experiments, GNL was added to the secondary antibody incubation buffer, for the costaining of the CL-11 and mannosyl residues. Images were obtained by wide-field fluorescence microscopy (Olympus BX-51, Olympus) or confocal microscopy (Nikon A1R; Nikon).

\section{Immunocytochemistry}

The RPE cells grown on coverslips were fixed with 4\% PFA for $10 \mathrm{~min}$ and then stained with primary antibodies (i.e., rabbit antimouse SIRP $\alpha$, rabbit anti-mouse calreticulin, and goat anti-mouse CL-11) at $4^{\circ} \mathrm{C}$ overnight, followed by incubation with fluorophore-conjugated secondary antibodies (i.e., donkey anti-goat Alexa Fluor 568 and goat anti-rabbit Alexa Fluor 568 or 488) for $1 \mathrm{~h}$ at room temperature. In some experiments, these cells were pretreated with recombinant (r)CL-11 for $1 \mathrm{~h}$ or rCL-11-opsonized POS for $30 \mathrm{~min}$. Nuclear counterstaining was performed using DAPI. Images were obtained by wide-field fluorescence microscopy or confocal microscopy (as above).

\section{Detection of Mannosyl Residue Expression in Eye Tissue and} RPE Cells

Cryosections of eye tissues or RPE cells grown on coverslips were fixed with $4 \%$ PFA for $10 \mathrm{~min}$ and then stained with fluorescein-labeled GNL, LCA, LTL, or UEA-I $(20 \mu \mathrm{g} / \mathrm{mL}$ in PBS) and DAPI $(1: 10,000)$. Mannose residue expression was analyzed by wide-field fluorescence microscopy. In some experiments, RPE cells were detached by trypsinization, followed by lectin staining and flow cytometry.

\section{Preparation of POS and Apoptotic Cells}

POS were isolated from bovine eyes according to established protocols. In brief, under dim red light, retinae were collected in a buffer from opened eyecups, cut in half. The retinal cell suspension was homogenized, filtered and loaded onto a continuous (25-60\%) sucrose gradient and followed by ultracentrifuge at $106,000 \mathrm{~g}$ for $50 \mathrm{~min}$ at $4^{\circ} \mathrm{C}$. After centrifugation, POS located in a discrete band in the upper part of the gradient that had a characteristic orange color were collected, washed, and labeled with fluorophores (FITC). The FITC-labeled POS were used for phagocytosis assays. Apoptotic Jurkat cells were prepared as previously described [22]. In brief, Jurkat cells were first labeled with 5(6)-TAMRA. The labeled cells were then exposed to UV light $(800 \mathrm{~mJ})$ and further cultured in RPMI 1640 containing 10\% FCS for $1 \mathrm{~h}$. Prior to phagocytosis assays, the POS and apoptotic Jurkat cells were incubated with or without $\mathrm{rCL}-11$ (300 or $600 \mathrm{ng} / \mathrm{mL}$ ) in the presence of $2 \mathrm{mM}$ calcium in the incubation buffer at $37^{\circ} \mathrm{C}$ for $1 \mathrm{~h}$, and then thoroughly washed with PBS.

\section{Microscopy-Based Phagocytosis Assay}

The primarily cultured B6-RPE07 grown on coverslips were incubated with CL-11-opsonized or nonopsonized, FITC-conjugated POS, or TAMRA-conjugated apoptotic Jurkat cells at $37^{\circ} \mathrm{C}$ for $1 \mathrm{~h}$. After thorough washing with PBS, the RPE cells were fixed in $4 \%$ PFA for $30 \mathrm{~min}$, permeablized in $0.2 \%$ Triton X-100 for $3 \mathrm{~min}$, and then stained with DAPI $(1: 10,000)$ and Alexa 568 phalloidin or Alexa 488 phalloidin. RPE cells were viewed and imaged with wide-field fluorescence microscopy; 6 individual fields from each coverslip were photographed. The number of POS/apoptotic Jurkat cells and DAPI in each image $(\times 200)$ was quantified by
Collectin-11 Modulates RPE Cell

Function
J Innate Immun 2017;9:529-545

DOI: $10.1159 / 000478042$ 
manual counting and expressed as the ratio of POS/apoptotic Jurkat cells to DAPI. Confocal microscopy was used to demonstrate the POS phagocytosed by the RPE cells.

Flow Cytometry-Based Phagocytosis Assay

B6-RPE07 cells grown on 24-well plates were incubated with rCL-11-opsonized or nonopsonized POS (for $2 \mathrm{~h}$ ) or apoptotic Jurkat cells (for $1 \mathrm{~h}$ ) at $37^{\circ} \mathrm{C}$. After thorough washing with PBS, cells were incubated with $2 \%$ trypan blue in HEPES buffer for 10 min (for fluorescence quenching), to minimize the fluorescence intensity of extracellularly bound POS or apoptotic cells. The RPE cells were then detached by incubation with $0.025 \%$ trypsinEDTA. The suspension cells were collected and fixed in 1\% PFA in PBS for flow cytometry. The phagocytosis of POS or apoptotic cells (or RPE associated with POS or apoptotic cells, i.e., phagocytosed/ bound) was measured by geometric mean fluorescence intensity. For the calreticulin blockade experiment, prior to incubation with POS, B6-RPE07 cells were incubated with control (rabbit IgG) or rabbit anti-calreticulin antibody $(10 \mu \mathrm{g} / \mathrm{mL})$ for $20 \mathrm{~min}$ at room temperature.

\section{Detection by Flow Cytometry of CL-11 Binding to RPE Cells} and POS

Binding of CL-11 to RPE cells was measured by flow cytometry analysis following the incubation of B6-RPE07 cells with nonconjugated rCL-11 $(600 \mathrm{ng} / \mathrm{mL})$ and immunochemical staining for CL-11. Binding of CL-11 to POS was measured by flow cytometry analysis following the incubation of POS with FITC-conjugated $\mathrm{rCL}-11(600 \mathrm{ng} / \mathrm{mL})$ at $37^{\circ} \mathrm{C}$ for $1 \mathrm{~h}$ and thorough washing with PBS.

Treatment with $\alpha$-Mannosidase

B6-RPE07 cells were preincubated with FCS-free medium for $2 \mathrm{~h}$ and then incubated with $\alpha$-mannosidase $(0,2.5$, and $5 \mathrm{mM})$ in glycol buffer 3 at $37^{\circ} \mathrm{C}$ for $2 \mathrm{~h}$. FCS-containing culture medium was added to neutralize the effect of mannosidase. Cells were fixed in $4 \%$ PFA in PBS for $15 \mathrm{~min}$, and then subjected to measuring changes in mannosyl residue expression and CL-11 binding and cytokine production following CL-11 stimulation.

\section{CL-11 Stimulation and Cytokine Detection}

B6-RPE07 cells grown on 24-well plates were incubated with medium alone, LPS $(10 \mathrm{ng} / \mathrm{mL})$, or IFN- $\gamma(500 \mathrm{U} / \mathrm{mL})$ for $1.5 \mathrm{~h}$, and continued to incubate with rCL-11 (300 ng/mL, $600 \mathrm{ng} / \mathrm{mL}$ ) for $24 \mathrm{~h}$. Supernatants were collected and used for the detection of IL- 10 and IL- 6 by ELISA using ELISA kits. For the SIRPa blockade experiment, prior to CL-11 stimulation, B6-RPE07 cells were pretreated with rat anti-SIRPa antibody (1:100 dilution) or rat IgG1 $\kappa$ (1:100) for $30 \mathrm{~min}$ at room temperature. For the experiment of blocking the interaction of CL-11 with carbohydrate ligands, B6RPE07 cells were pretreated with $\alpha$-mannosidase $(0,2.5,5 \mathrm{mM})$ in glycol buffer 3 at $37^{\circ} \mathrm{C}$ for $2 \mathrm{~h}$.

\section{$R T-P C R$}

Total RNA was extracted from the mouse eye tissue, RPE-choroid complex, primarily cultured RPE cells, and B6-RPE07 cells using TRIzol reagent. Complementary DNA (cDNA) was synthesized in a $25-\mu \mathrm{L}$ reverse-transcription reaction mix consisting of $2 \mu \mathrm{g}$ of total RNA, $0.5 \mu \mathrm{g}$ Oligo(dT) 12-18 primer, $10 \mathrm{~mm}$ nucleotide mixture, $25 \mathrm{U}$ recombinant RNasin ribonuclease inhibitor, and $200 \mathrm{U}$ M-
MLV reverse transcriptase. Each PCR was carried out in a $25-\mu \mathrm{L}$ volume with cDNA reflecting $0.15 \mu \mathrm{g}$ RNA, $12.5 \mu \mathrm{L}$ GoTaq G2 Green master mix, and $2 \mu \mathrm{M}$ of each primer. DNA was denatured at $94^{\circ} \mathrm{C}$, annealed at $60^{\circ} \mathrm{C}$, and extended at $72^{\circ} \mathrm{C}$, with a total of 40 reaction cycles. Amplified PCR products were electrophoresed in a $2 \%$ agarose gel and photographed under ultraviolet light. The following primers were used: murine Colec11: forward, $5^{\prime}$-TTCGCCTAGTGTGCATCCAG-3' and reverse, $5^{\prime}$-GCGCCAATGGGACCAATTTT-3'; Calreticulin: forward, 5'-CTGTTTCCGAGTGGTTTGGA- $3^{\prime}$ and reverse $5^{\prime}$-CTTCTTAGCATCAGGGTCAGGG-3'; SIRPa: forward, 5'-GGGACCCATTAGGTGGTACA-3' and re-

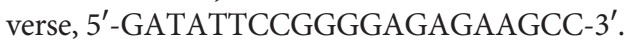

\section{Western Blot}

Supernatants of primarily cultured mouse RPE cells were collected, subjected to SDS-PAGE, and transferred onto a PVDF membrane. The membrane was incubated with goat anti-human CL-11 antibody at $4{ }^{\circ} \mathrm{C}$ overnight, followed by incubation with HRP-conjugated rabbit anti-goat IgG antibody. Protein bands were visualized by Amersham ECL Select ${ }^{\mathrm{TM}}$ detection reagent.

\section{Statistical Analysis}

Data are shown as mean \pm SEM. The unpaired two-tailed Student $t$ test was used to compare the means of 2 groups. One-way ANOVA with or without Tukey post hoc test was used to compare the means of $>2$ groups. All the analyses were performed using GraphPad Prism software (La Jolla, CA, USA). $p<0.05$ was considered to be significant.

\section{Results}

\section{CL-11 Is Produced in the Neural Retina}

To assess the possibility that local production of CL-11 by the retina is involved in retinal pathophysiology, we thoroughly examined the production of CL-11 in the mouse retina. RT-PCR showed that Colec11 mRNA was detected in the neural retina, RPE-choroid complex, and primarily cultured RPE cells (with or without TFN- $\alpha / \mathrm{IL}-$ $1 \beta$ stimulation) prepared from WT B6 mice. In addition to the predicted 372 -bp product, a smaller product (approx. $230 \mathrm{bp}$ ) was also detected in some samples, which may reflect an additional transcript of Colec11 $[4,13]$ (Fig. 1a, b). Immunohistochemistry on mouse eye tissues showed that CL-11 was clearly detected in the neural retinas of WT mice but was not detected in Colec11 KO (CL$11^{-/-}$) mice; positive staining was observed in PRC (i.e. inner segments, POS) and RPE cells (Fig. 1c). Expression of CL-11 in RPE cells was further confirmed by immunohistochemistry on flat-mounted RPE-choroid complex (Fig. 1d). Western blot showed that a $38-\mathrm{kDa}$ band corresponding to $\mathrm{rCL}-11$ was detected in the supernatants of RPE primary cultures, indicating that CL-11 can be secreted extracellularly by RPE. A strong band at approxi-
532

J Innate Immun 2017;9:529-545

DOI: $10.1159 / 000478042$
Dong/Wu/Ma/Liu/Bhuckory/Wang/

Nandrot/Xu/Li/Liu/Zhou 


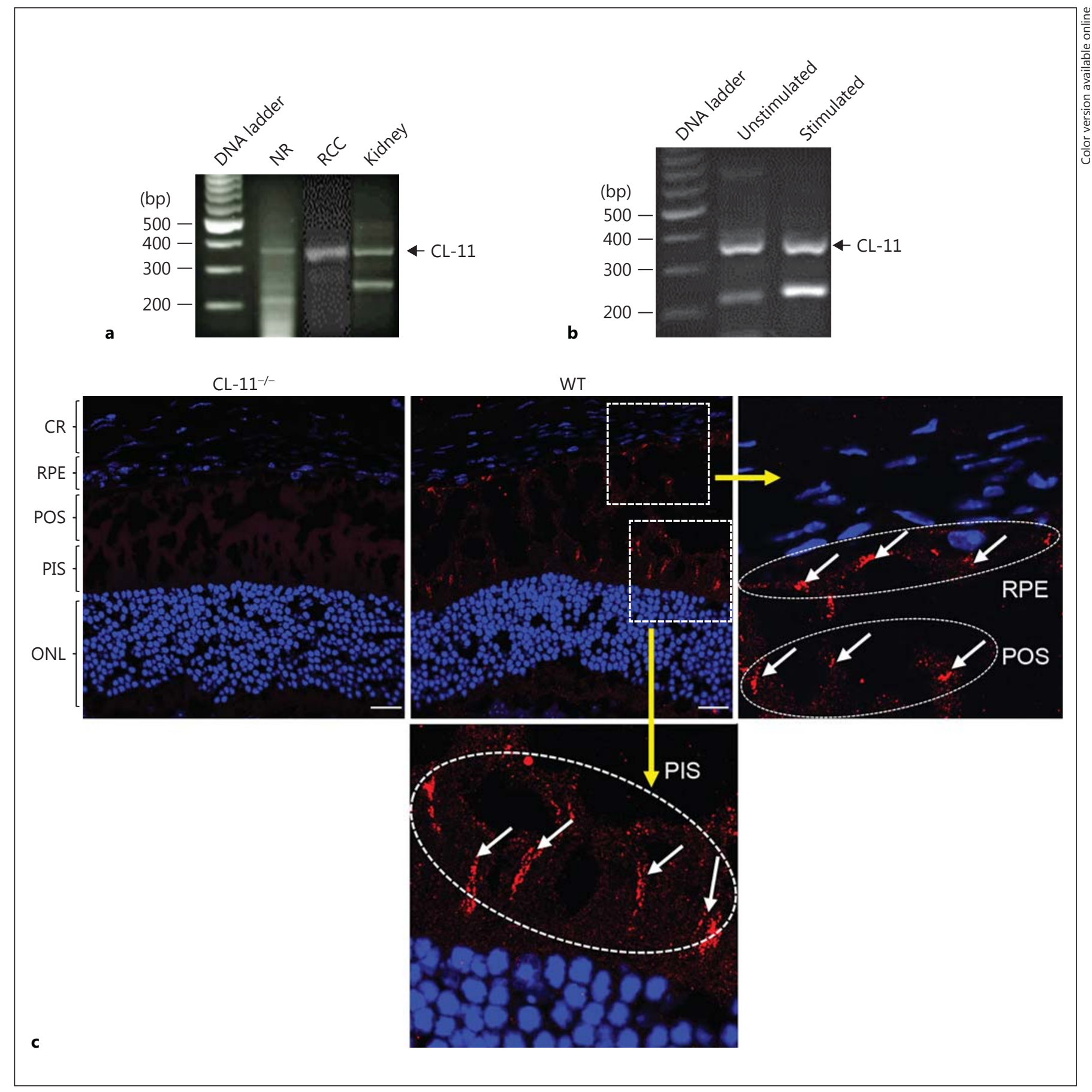

Fig. 1. CL-11 is produced in the neural retina and RPE. a RT-PCR on dissected neural retinas (NR) and RPE-choroid complex (RCC) and kidney tissues (used as a positive control) from WT B6 mice. b RT-PCR on mouse primary RPE cells that had been stimulated with (stimulated) or without (unstimulated) TNF- $\alpha /$ IL- $1 \beta$ for $24 \mathrm{~h}$. c Fluorescence microscopy images of immunohistochemical staining of CL-11 (red) in eye tissue of WT and CL-11 ${ }^{-/-}$mice; nuclear marker DAPI (blue) is also shown. Bottom and right: higher-magnification images that correspond with boxed areas. CR, choroid; RPE, retinal pigment epithelium; POS, photoreceptor outer segments; PIS, photoreceptor inner segments; ONL, outer nuclear layer. Scale bar, $20 \mu \mathrm{m}$. d Fluorescence microscopy images of immunochemical staining for CL-11 (red) and ZO-1 (a tight junction protein) (green) in flat-mounted RPE-choroid complex of WT and CL-11 $1^{-/-}$mice. Scale bar, $10 \mu \mathrm{m}$. e Western blot for CL11 on rCL-11 (used as a positive control) and supernatants of mouse primary RPE cells stimulated with TNF- $\alpha / \mathrm{IL}-1 \beta$ for $24 \mathrm{~h}$ or were left unstimulated. a-e A representative of 3 experiments is shown.

(Figure continued on next page.)
Collectin-11 Modulates RPE Cell Function
J Innate Immun 2017;9:529-545 DOI: $10.1159 / 000478042$ 


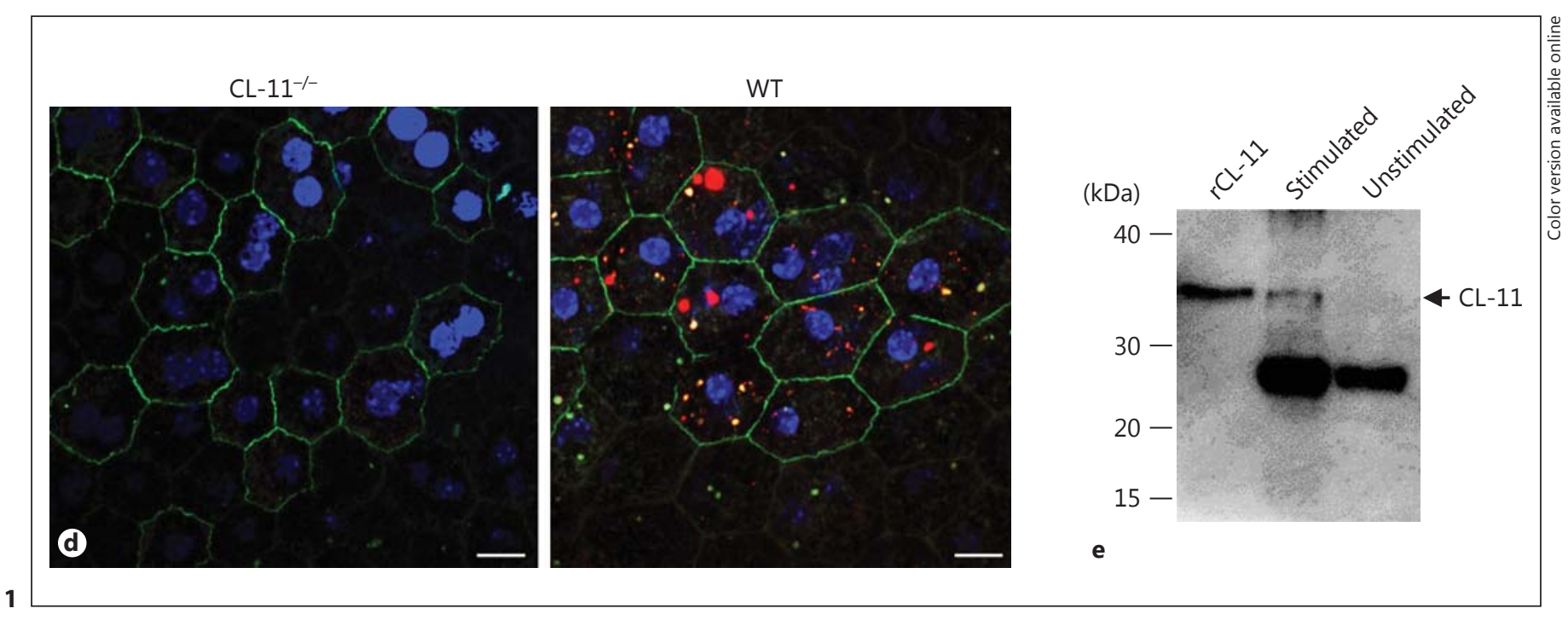

mately $28 \mathrm{kDa}$ was also detected, which may reflect the isoforms of CL-11, as previously reported $[4,13]$ (Fig. 1e). To assess the relevance of these findings for the human retina, we performed immunohistochemistry on postmortem human eyes for CL-11. CL-11 was detected in the human retina, with positive staining observed in PRC, RPE, and the outer nuclear layer (online suppl. Fig. 1a; for all online suppl. material, see www. karger.com/doi/10.1159/000478042), which is consistent with the previously reported detection of the Colec11 mRNA transcript in human retina [13]. Taken together, these observations demonstrate that CL-11 is produced in murine and human neural retina.

\section{Detection of Carbohydrate Residue Expression in POS and $R P E$}

We examined the expression of carbohydrate residues in the neural retina. Previous studies have shown that CL11 preferentially binds to L-fucose, D-mannose, and highmannose glycans, among other possible monosaccharide ligands $[4,13,23]$. We therefore performed lectin staining in mouse eye tissue, using 2 fluorescein-labeled lectins: GNL (for detecting structures containing terminal [ $\alpha-1,3]$ mannosyl residues) and LCA (for detecting branched fucose/a-linked mannose residues). Fluorescence microscopy clearly revealed that both POS and RPE were positively stained with GNL and LCA. GNL-positive staining was mainly observed in PRC including POS and RPE, while LCA-positive staining was more widely distributed in the neural retina (Fig. 2a). We also performed lectin staining in human eye tissue and found that both
PRC and RPE were positively stained with GNL and LCA, which indicates the presence of mannosyl residues on the human retina (online suppl. Fig. 1a). To evaluate the spatial relationship between CL-11 and mannosyl residues, we performed costaining in mouse eye tissues. Fluorescence microscopy showed that CL-11 and GNL signals were in close proximity to each other on the POS and RPE cells (Fig. 2b). Together, these observations demonstrate that mannosyl residues are expressed on POS and RPE, which are also closely associated with CL-11, thus supporting the hypothesis that CL-11 interacts with POS or RPE cells through binding to its carbohydrate ligands in the retina.

\section{CL-11 Facilitates Opsonophagocytosis of} POS/Apoptotic Cells by RPE Cells

We investigated whether CL-11 can function as an opsonin to facilitate the phagocytosis of POS/apoptotic cells by RPE cells. We first examined the ability of CL-11 to bind POS. Flow cytometry analysis showed that CL-11 was detected on the surface of POS following the incubation of POS with rCL-11 for $1 \mathrm{~h}$ (Fig. 3a), suggesting that CL-11 can bind to POS and may function as an opsonin. Next, we assessed the effect of CL-11 on opsonophagocytosis of POS by RPE cells. CL-11-opsonized or nonopsonized POS (fluorescein-labeled) were incubated with primarily cultured mouse RPE cells for $1 \mathrm{~h}$, followed by thorough washing and fluorescence quenching. Fluorescence microscopy analysis showed that significantly more CL11-opsonized than nonopsonized POS were associated with RPE cells (Fig. 3b, c). The confocal $z$-stack images 


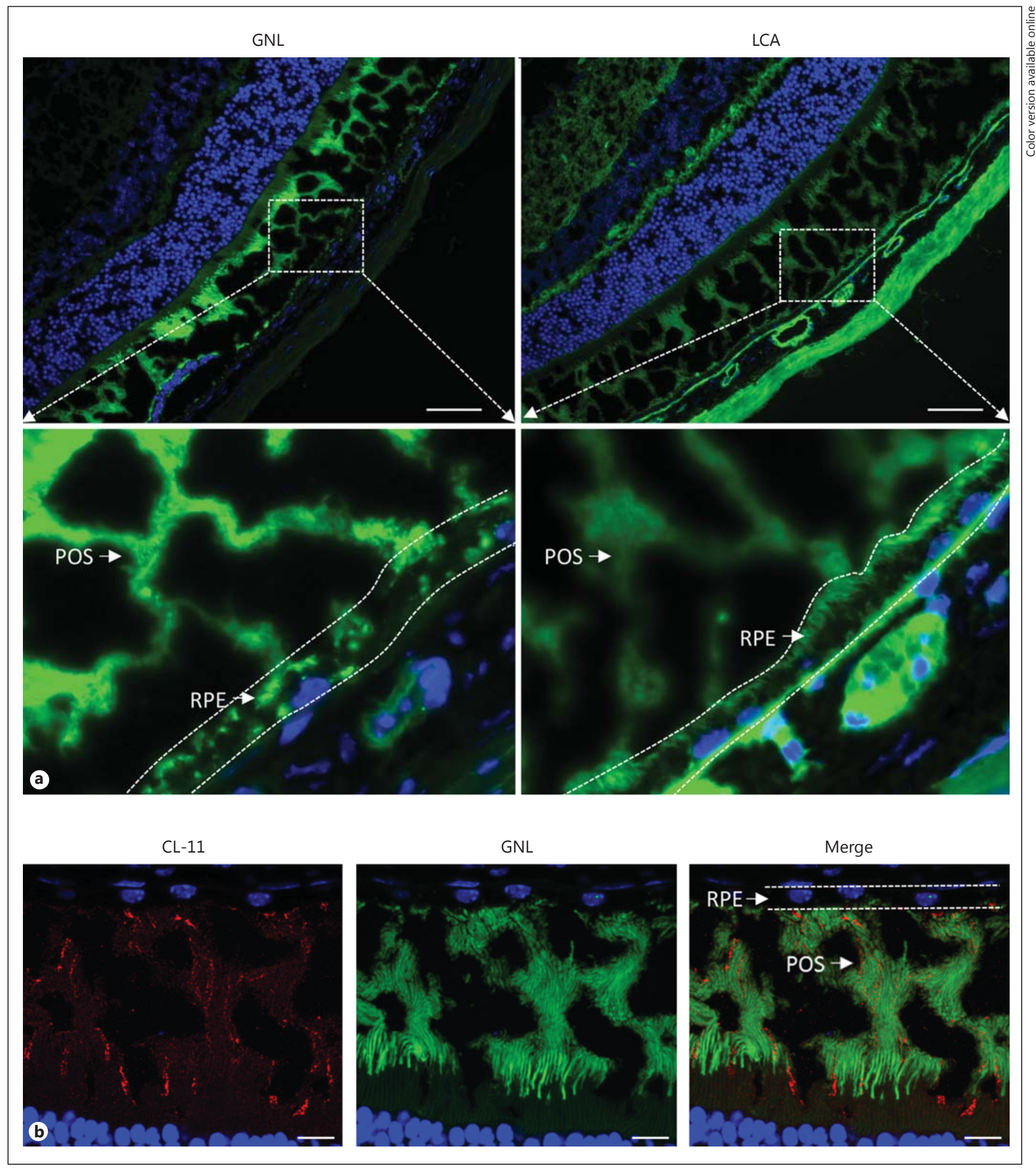

Fig. 2. Detection of carbohydrate residue expression in PRC and PRE. a Fluorescence microscopy images of staining with GNL and LCA (green), and DAPI (blue) in the mouse eye. Bottom: highermagnification images that correspond with the boxed areas. Scale bar, $50 \mu \mathrm{m}$. b Fluorescence microscopy images of immunochemical staining for CL-11 (red) and GNL (green) in the mouse eye. Scale bar, $10 \mu \mathrm{m}$. A representative of 3 experiments is shown.
Collectin-11 Modulates RPE Cell Function
J Innate Immun 2017;9:529-545 DOI: $10.1159 / 000478042$ 


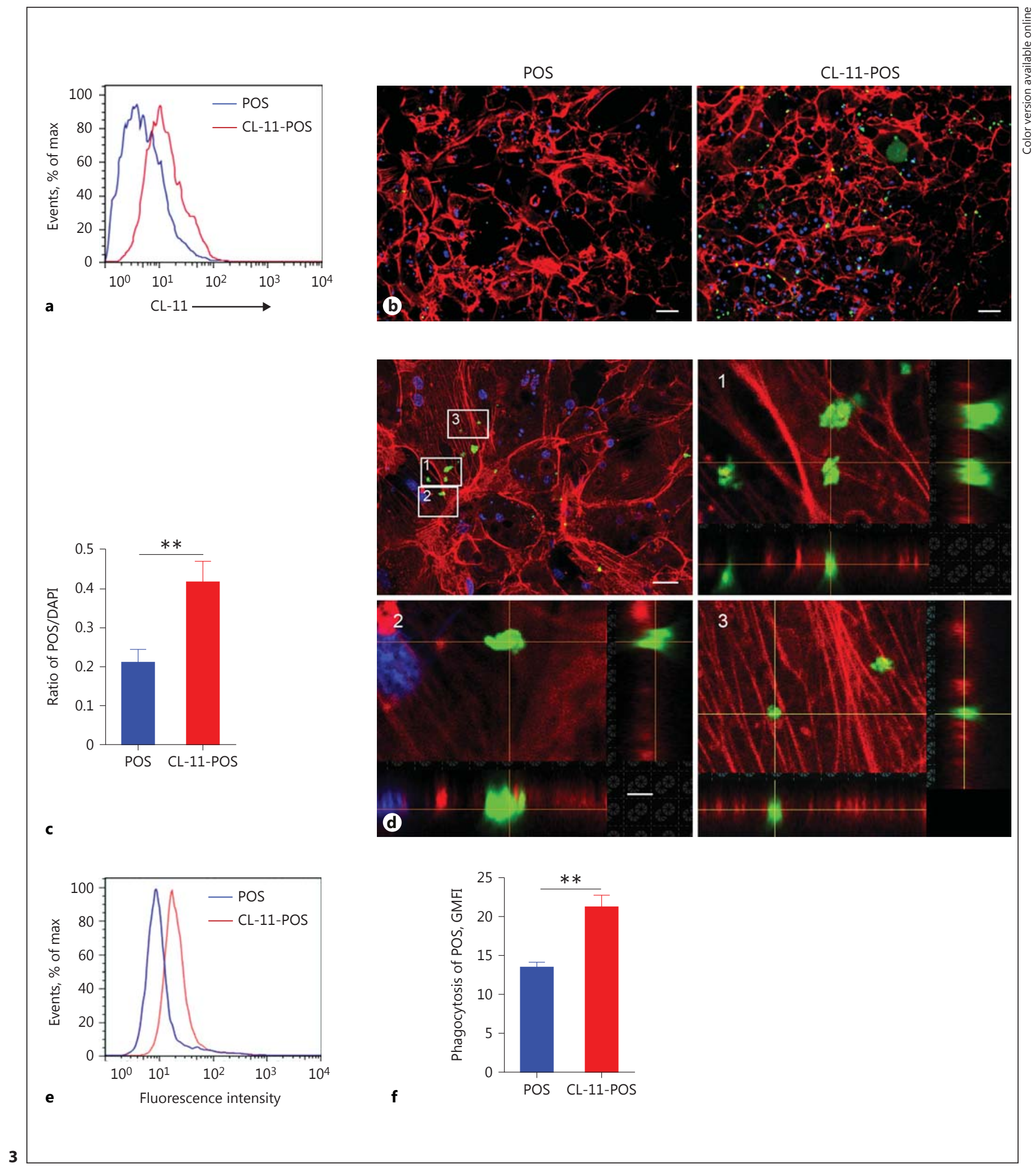

(Figure continued next page.) 


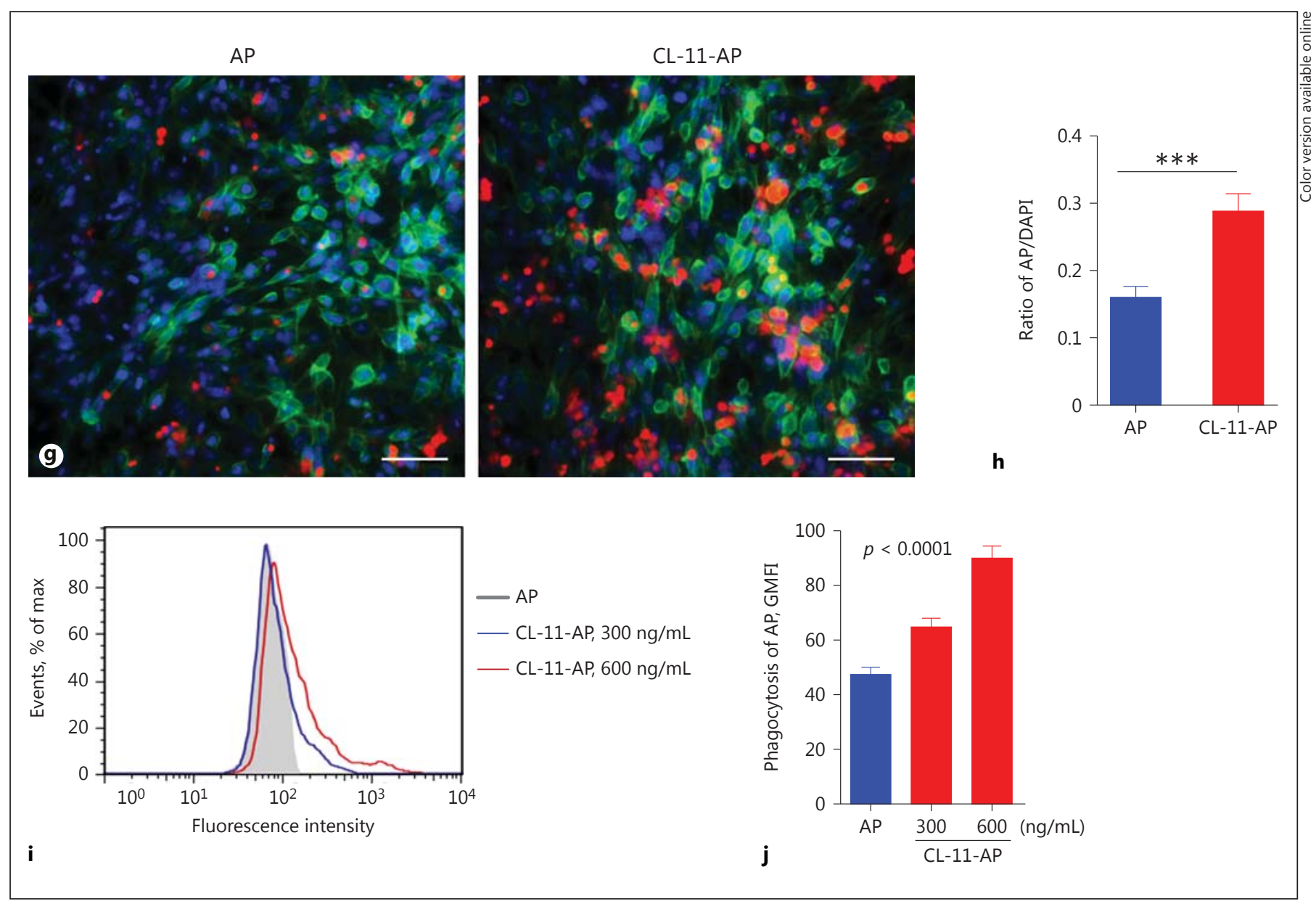

Fig. 3. CL-11 facilitates opsonophagocytosis of POS/apoptotic cells by RPE cells. a Flow cytometry analysis of CL-11 binding to POS incubated with FITC-labeled rCL-11 (600 ng/mL) for $1 \mathrm{~h} . \mathbf{b}$ Fluorescence microscopy images of primarily cultured mouse RPE incubated with nonopsonized POS (POS) or CL-11 (600 ng/mL) opsonized POS (CL-11-POS) for $1 \mathrm{~h}$, followed by thorough washing and fluorescence quenching; POS were prelabeled with FITC (green), RPE cells were stained with phalloidin (red), nuclear staining was with DAPI (blue). Scale bar, $50 \mu \mathrm{m}$. c Quantification of POS associated with RPE cells corresponds to $\mathbf{b}$. Data are from 6 individual images (from 2 coverslips) per group and representative of 3 independent experiments. ${ }^{* *} p<0.01$, unpaired two-tailed Student $t$ test. $\mathbf{d}$ Confocal images corresponding to the CL-11-POS image in $\mathbf{b}$. The $z$-stack image shows POS (green) phagocytosed by RPE cells (stained with phalloidin [red]). Scale bar, $25 \mu \mathrm{m}$. e Flow cytometry analysis of uptake of POS in B6-RPE07 cells incubated with nonopsonized POS (POS) or CL-11 (600 ng/mL) opsonized POS (CL-11-POS for $2 \mathrm{~h}$, followed by thorough washing and fluorescence quenching. $\mathbf{f}$ Quantification of POS associated with RPE cells (histogram e), shown as geometric mean of fluorescence in- tensity (GMFI). Data are from 4 cell samples per group and were analyzed by unpaired two-tailed Student $t$ test. ${ }^{* *} p<0.01$. g Fluorescence microscopy images of B6-RPE07 cells incubated with nonopsonized apoptotic cells (AP) or rCL-11 (600 ng/mL) opsonized apoptotic cells (CL-11-AP) for $1 \mathrm{~h}$, followed by thorough washing and fluorescence quenching; apoptotic cells were prelabeled with TAMRA (red), RPE was stained with phalloidin (green), nuclear staining was with DAPI (blue). Scale bar, $50 \mu \mathrm{m}$. h Quantification of apoptotic cells associated with RPE cells corresponds to e. Data shown are from 6 individual images (from 3 coverslips) per group and were analyzed by unpaired two-tailed Student $t$ test. *** $p<0.0001$. i Flow cytometry analysis of uptake of AP in B6RPE07 cells incubated with AP or CL-11-AP (preincubated with indicated concentrations of rCL-11). Apoptotic cells were prelabeled with TAMRA. j Quantification of apoptotic cells associated with RPE cells (histogram i), shown as geometric mean of fluorescence intensity (GMFI). Data are from 4 cell samples per group and were analyzed with one-way ANOVA, comparing the nonopsonized AP with the CL-11-opsonized AP. e-j A representative of 3 independent experiments is shown.
Collectin-11 Modulates RPE Cell Function
J Innate Immun 2017;9:529-545 DOI: $10.1159 / 000478042$ 
Fig. 4. CL-11 regulates inflammatory cytokine production by RPE cells. B6-RPE07 cells were cultured with or without rCL-11, in the absence or presence of LPS (10 ng/ $\mathrm{mL})$ or IFN- $\gamma(500 \mathrm{U} / \mathrm{mL})$ for $24 \mathrm{~h}$. Supernatants were collected and used for ELISA. a IL-10. b IL-6. Data are from 4 individual cell culture plate wells per group and were analyzed with one-way ANOVA, comparing the untreated and CL-11-treated samples. A representative of 3 independent experiments is shown.

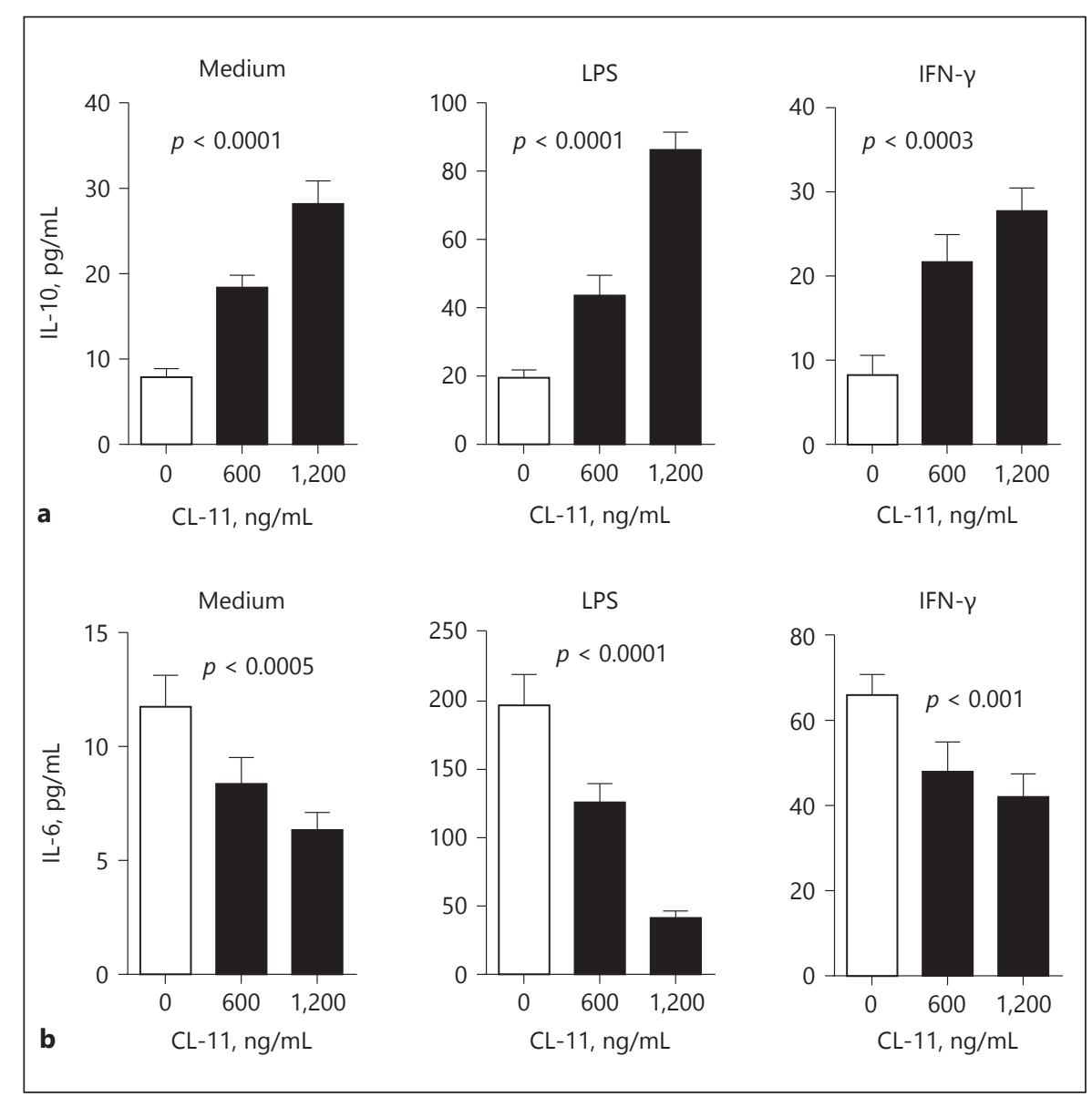

further revealed that POS associated with RPE cells (observed in Fig. 3b) were localized intracellularly within RPE cells, suggesting that phagocytosis had occurred (Fig. 3d). The effect of CL-11 on the opsonophagocytosis of POS by RPE cells was further evaluated in B6-RPE07 cells using flow cytometry. The phagocytosis of POS by RPE cells was significantly enhanced by preincubation of POS with rCL-11 (Fig. 3e, f). In addition to POS, we also assessed the effect of CL-11 on the opsonophagocytosis of apoptotic cells by RPE cells. CL-11-opsonized or nonopsonized apoptotic cells (fluorescein labeled) were incubated with B6-RPE07 cells for $1 \mathrm{~h}$, followed by thorough washing and fluorescence quenching. Fluorescence microscopy and flow cytometry analyses showed that significantly more CL-11-opsonized than nonopsonized apoptotic cells were associated with RPE cells (Fig. 3g-j). These data clearly demonstrate a role for CL-11 in the opsonophagocytosis of POS and apoptotic cells by RPE cells.

\section{CL-11 Regulates Inflammatory Cytokine Production by RPE Cells}

We investigated whether CL-11 has effects on inflammatory cytokine production. B6-RPE07 cells were stimulated with $\mathrm{rCL}-1$, in the absence or presence of pathological stimuli (LPS or IFN- $\gamma$ ). ELISA showed that CL-11 stimulation clearly increased the production of IL-10 by the RPE cells; this was observed in the absence or presence of LPS or IFN- $\gamma$ (Fig. 4a). On the contrary, CL-11 stimulation led to a decrease in IL- 6 production by the RPE cells (Fig. 4b). Together, these results suggest that CL-11 has different regulatory effects on the production of IL- 10 and IL- 6 by RPE cells, i.e., it upregulates IL-10 production and downregulates IL-6 production.

\section{Identification of the Receptor Responsible for}

CL-11-Mediated Opsonophagocytosis by RPE Cells

The observation of the effect of CL-11 on opsonophagocytosis by RPE cells raises the question of which receptor/molecule on RPE cells is responsible for the 


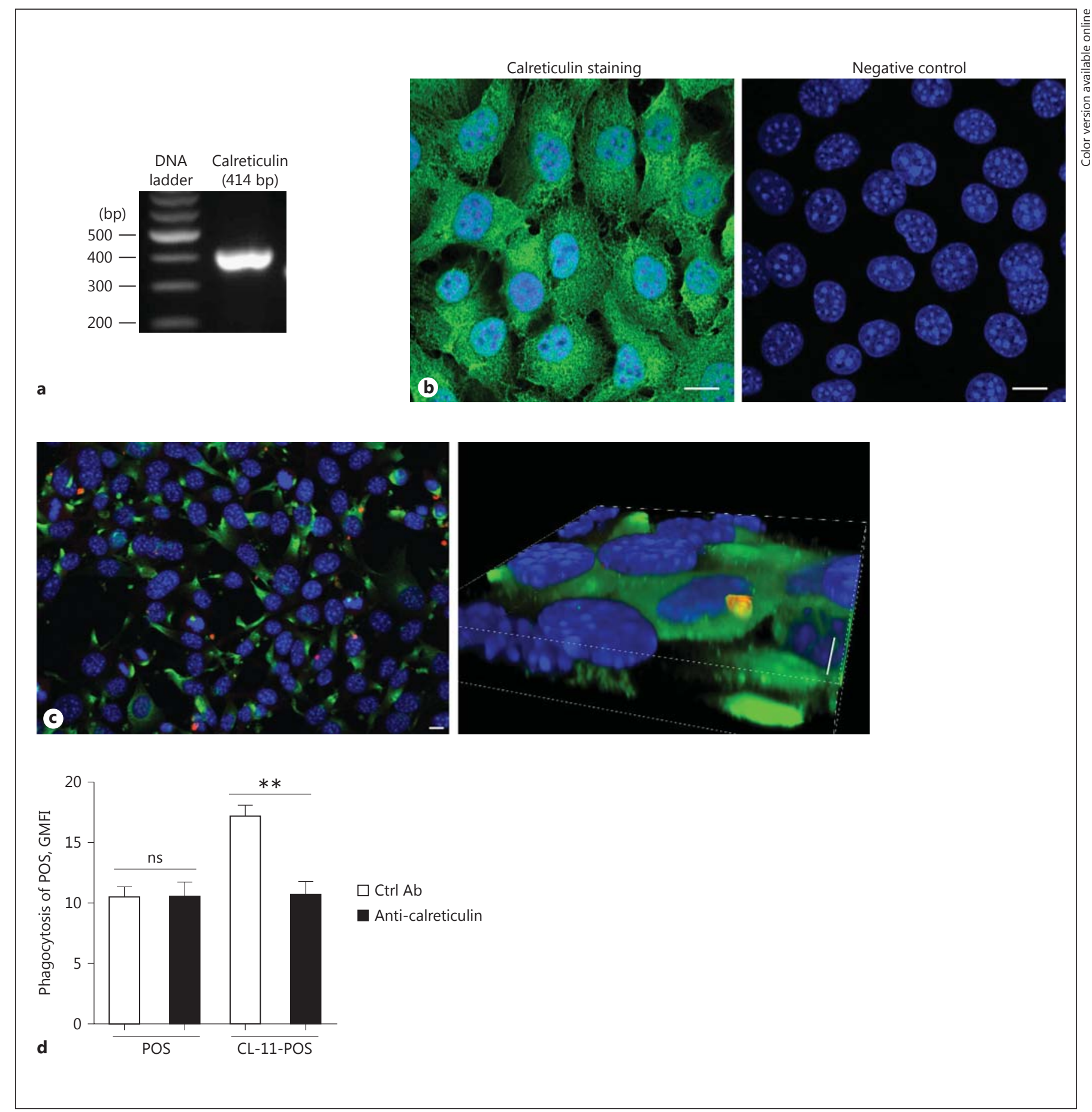

Fig. 5. Identification of the receptor responsible for CL-11-mediated opsonophagocytosis by RPE cells. a Detection of calreticulin in B6-RPE07 cells by RT-PCR. b Fluorescence microscopy images of B6-RPE07 cells (from 2 independent experiments) stained for calreticulin (green) and the nuclear marker DAPI (blue). Negative control: the staining was performed using 2 nd antibody alone. Scale bar, $10 \mu \mathrm{m}$. c Confocal images of B6-RPE07 cells (at low and high magnifications) incubated with rCL-11-opsonized POS for $30 \mathrm{~min}$ and subjected to staining for CL-11 (red) and calreticulin (green) and the nuclear marker DAPI (blue). Scale bar, $10 \mu \mathrm{m}$. A representative of 2 independent experiments is shown. d Flow cytometry analysis of phagocytosis of POS (prelabeled with FITC) by B6RPE07 cells pretreated with anti-calreticulin antibody or control antibody (Ctrl Ab), and then incubated with nonopsonized POS (POS) or CL-11-opsonized (CL-11-POS) for $2 \mathrm{~h}$. Data are from 4 cell samples per group and were analyzed with one-way ANOVA with the Tukey post hoc test. ${ }^{* *} p<0.01$; ns, no significant difference. A representative of 3 independent experiments is shown.
Collectin-11 Modulates RPE Cell Function
J Innate Immun 2017;9:529-545 DOI: $10.1159 / 000478042$ 
action of CL-11. Calreticulin (a reported coreceptor for CD91) has been shown to bind to the collectins (e.g., MBL and surfactant proteins) and C1q, and to be involved in the opsonophagocytosis of apoptotic cells by macrophages. Inspired by these findings, we sought to investigate whether calreticulin is involved in CL-11-mediated opsonophagocytosis by RPE cells. We first examined whether calreticulin is expressed on RPE cells. Calreticulin was clearly detected in cultured B6-RPE07 cells by RTPCR and immunocytochemistry (Fig. 5a, b), and on the RPE-choroid complex by immunochemistry (online suppl. Fig. 2). We then assessed whether CL-11-opsonized POS binds to calreticulin on RPE cells. Confocal microscopy showed a strong association of CL-11-POS with calreticulin on RPE cells (Fig. 5c). We next assessed whether calreticulin blockade using an anti-calreticulin antibody has an effect on the phagocytosis of CL-11opsonized POS by RPE cells. Flow cytometry analysis showed that phagocytosis of CL-11-POS by RPE cells was significantly reduced by prior treatment with the anti-calreticulin antibody; however, this reduction was not observed in nonopsonized POS (Fig. 5d). These results support that calreticulin is involved in CL-11-mediated opsonophagocytosis by RPE cells.

Identification of the Receptor/Molecule Involved in the CL-11-Mediated Modulation of Cytokine Production by RPE Cells

SIRPa (an ITIM-containing inhibitory receptor) is mainly expressed on myeloid cells (e.g., macrophages), but also on other cells (e.g., stem cells), and it mediates various cellular responses (e.g., inflammatory cytokine production) upon engagement. Cell-surface protein CD47 is the well-known ligand for macrophage SIRPa [24]. Soluble ligands such as surfactant proteins A and D have also been shown to bind to SIRPa to regulate cytokine production by macrophages [25]. We hypothesized that CL-11 may also bind to SIRPa and regulate the production of cytokines by RPE cells. To test this, we first examined whether SIRPa is expressed by RPE cells and whether CL-11 binds to SIRPa. SIRPa was clearly detected in B6-RPE07 cells by RT-PCR and immunocytochemistry (Fig. 6a, b). The binding of CL-11 to SIRPa on B6RPE07 cells was clearly revealed by confocal microscopy following costaining for CL-11 and SIRPa after incubating RPE cells with rCL-11 (Fig. 6c). We then assessed whether the effect of CL-11 on RPE cytokine production could be inhibited by SIRPa blockade. ELISA showed that, with prior treatment of RPE cells with anti-SIRPa monoclonal antibody, CL-11-mediated upregulation of
IL-10 production by RPE cells was remarkably inhibited compared with control antibody-treated cells (Fig. 6d); there was no effect of anti-SIRPa antibody treatment on the RPE cell production of IL-10 in the absence of CL-11, suggesting that SIRPa is involved in CL-11-mediated IL10 production by RPE cells.

The immunohistochemistry data (Fig. 2a) indicated the presence of mannosyl residues on RPE cells. We therefore performed screening for carbohydrate moieties on B6-RPE07 cells using several lectin probes. The cells were positively stained by LCA or GNL, but negatively stained by LTL or UEA-I (which detects L-fucose and/or fucose residues), suggesting that mannosyl residues but not fucose residues are the major carbohydrate ligand on RPE cells for CL-11 (Fig. 6e). We then assessed whether mannosyl residues can be effectively removed by prior treatment of RPE cells with $\alpha$-mannosidase (which cleaves mannose-containing glycoproteins and glycolipids) and whether the removal of mannosyl residues reduces the binding of CL-11 on B6-RPE07 cells. Flow cytometry analysis showed that, following a-mannosidase treatment, the expression of mannosyl residue on RPE cells and the subsequent binding of CL-11 to RPE cells were significantly reduced (Fig. 6f, g). We then went on to determine whether the effect of CL-11 on RPE cytokine production could be inhibited by the removal of mannosyl residues. ELISA showed that by prior treatment of RPE cells with a-mannosidase, CL-11-mediated upregulation of IL-10 production by RPE cells was significantly inhibited, while CL-11-mediated downregulation of IL-6 production was elevated compared with control (buffer alone)-treated cells (Fig. 6h, i). Taken together, these observations suggest that both SIRPa and mannosyl residues are involved in the CL-11-mediated modulation of cytokine production by RPE cells.

\section{Discussion}

Phagocytosis of shedded POS is a key function for RPE cells and vision. POS, like apoptotic cells, express phosphatidylserine (PS) on their surface, which can be recognized and subsequently phagocytosed by RPE cells. It is thought that RPE cells share similar clearance mechanisms to those used by other phagocytes (e.g., macrophages and dendritic cells) to phagocytose shedded POS [3]. Previous studies have shown that certain receptors on RPE cells, such as common phagocyte receptor (TAM receptor tyrosine kinase Mer) [26-28], scavenger receptor (CD36) [29], and the integrin adhesion receptor ( $\alpha \vee \beta 5)$
540

J Innate Immun 2017;9:529-545 DOI: $10.1159 / 000478042$
Dong/Wu/Ma/Liu/Bhuckory/Wang/

Nandrot/Xu/Li/Liu/Zhou 


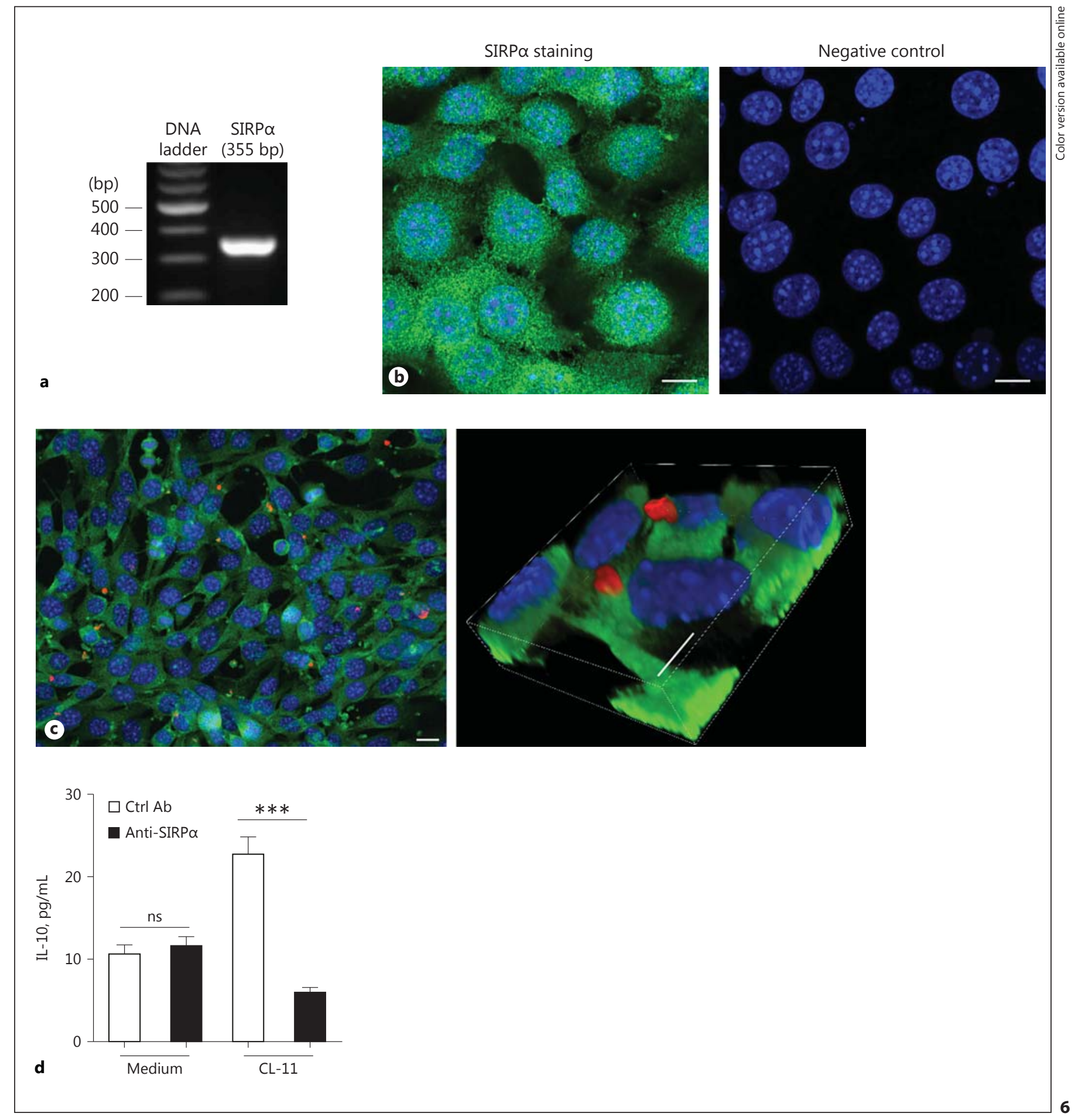

(Figure continued on next page.)

[30], are involved in the phagocytosis of shedded POS. However, little is known about the involvement of opsonization-mediated phagocytosis (a well-known mechanism in macrophages) in RPE cells. In this study, we dem-

Collectin-11 Modulates RPE Cell Function onstrated that CL-11 can bind to POS and that CL-11opsonized POS are phagocytosed more efficiently by RPE cells than nonopsonized POS. Similar observations were also made of the phagocytosis of apoptotic cells (CL-

J Innate Immun 2017;9:529-545 


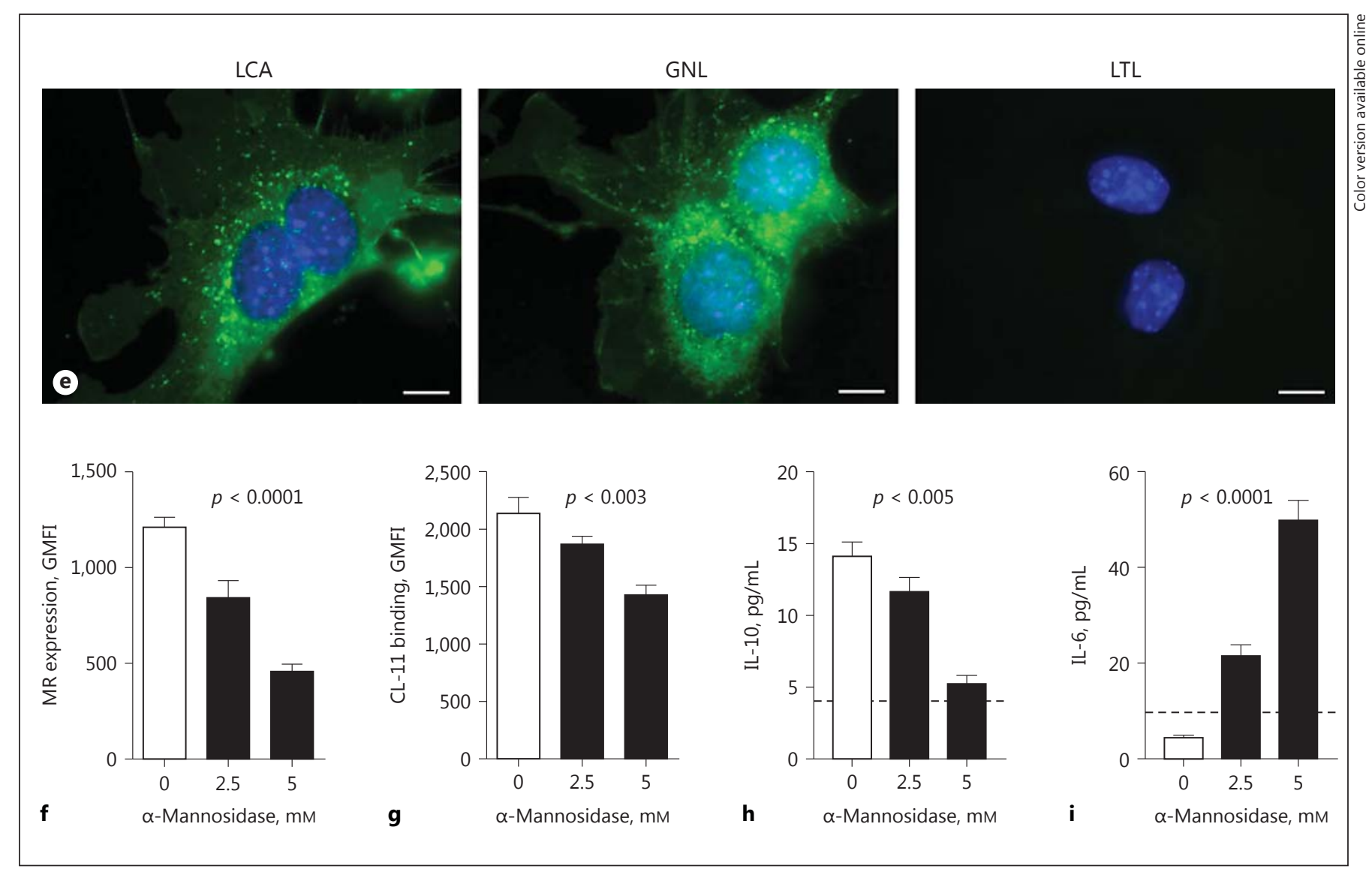

Fig. 6. Identification of the receptor/molecules involved in CL11-mediated modulation of cytokine production by RPE cells. a Detection of SIRPa in B6-RPE07 cells by RT-PCR. b Fluorescence microscopy images of B6-RPE07 cells (of 2 independent experiments) stained for SIRPa (green) and nuclear marker DAPI (blue). Negative control: the staining was performed using 2nd antibody alone. Scale bar, $10 \mu \mathrm{m}$. c Confocal images of B6-RPE07 cells (at low and high magnifications) incubated with rCL-11 (600 $\mathrm{ng} / \mathrm{mL}$ ) for $1 \mathrm{~h}$ and subjected to staining for CL-11 (red) and SIRPa (green) and nuclear marker DAPI (blue). Scale bar, $10 \mu \mathrm{m}$. A representative of 2 independent experiments is shown. d B6-RPE07 cells were pretreated with anti-SIPR $a$ antibody (1:100 diluted) or control antibody (Ctrl Ab) and then incubated with or without rCL-11 (600 ng/mL) for $24 \mathrm{~h}$. Supernatants were collected and used for measuring IL-10 by ELISA. Data are from 4 cell samples per group and were analyzed with one-way ANOVA with the Tukey post hoc test. ${ }^{* * *} p<0.001$; ns, no significance. A representative of 3 independent experiments is shown. e Fluorescence mi-

11-opsonized vs. nonopsonized). These findings suggest that CL-11 can function as an opsonin to mediate the opsonophagocytosis of POS (as well as apoptotic cells) by RPE cells, providing new insights into the mechanisms of phagocytosis of shedded POS. With regard to the recep- croscopy images of B6-RPE07 cells that had been stained with fluorescence-conjugated GNL, LCA, or LTL (green). Scale bar, 10 $\mu \mathrm{m}$. f Flow cytometry for the detection of mannosyl residue (MR) expression on B6-RPE07 cells that had been treated with buffer alone or containing $\alpha$-mannosidase for $2 \mathrm{~h}$, and then stained with fluorescence-conjugated LCA. $\mathbf{g}$ Flow cytometry analysis of CL-11 binding to B6-RPE07 cells treated with buffer or containing a-mannosidase for $2 \mathrm{~h}$, incubated with rCL-11 $(600 \mathrm{ng} / \mathrm{mL})$ for $1 \mathrm{~h}$, and then subjected to staining for CL-11. h, i B6-RPE07 cells were pretreated with buffer alone or containing $\alpha$-mannosidase at the indicated concentrations for $2 \mathrm{~h}$ and then incubated with rCL$11(600 \mathrm{ng} / \mathrm{mL})$ for $24 \mathrm{~h}$. Supernatants were collected and used for measuring IL-10 and IL- 6 by ELISA. The dashed line indicates the level of IL-10 or IL-6 in RPE cells without CL-11 stimulation. f-i Data are from 4 cell samples per group and were analyzed with one-way ANOVA, comparing the control (buffer alone) and a-mannosidase-treated cells. A representative of 3 independent experiments is shown.
542

J Innate Immun 2017;9:529-545

DOI: $10.1159 / 000478042$ tor responsible for CL-11-mediated opsonophagocytosis, we showed that calreticulin is expressed in RPE cells, CL11-POS can bind to calreticulin on RPE cells, and calreticulin blockade effectively inhibits the CL-11-mediated opsonophagocytosis of POS by RPE cells, thus supporting 
Fig. 7. A schematic diagram illustrates the proposed mechanisms by which CL-11 modulates RPE cell phagocytosis and cytokine production. Locally produced CL-11 (by RPE, photoreceptors, and possibly other cells): (i) binds to shed POS to mediate or upregulate the phagocytosis of POS through the interaction of the CL-11 collagen-like region (CLR) with calreticulin/ CD91 on RPE cells, (ii) binds to RPE cells to mediate the upregulation of IL-10 production through the interaction of the CL-11 carbohydrate domain (CRD) with a specific glycoprotein (SIRPa) and/or mannose-containing structures on RPE cells.

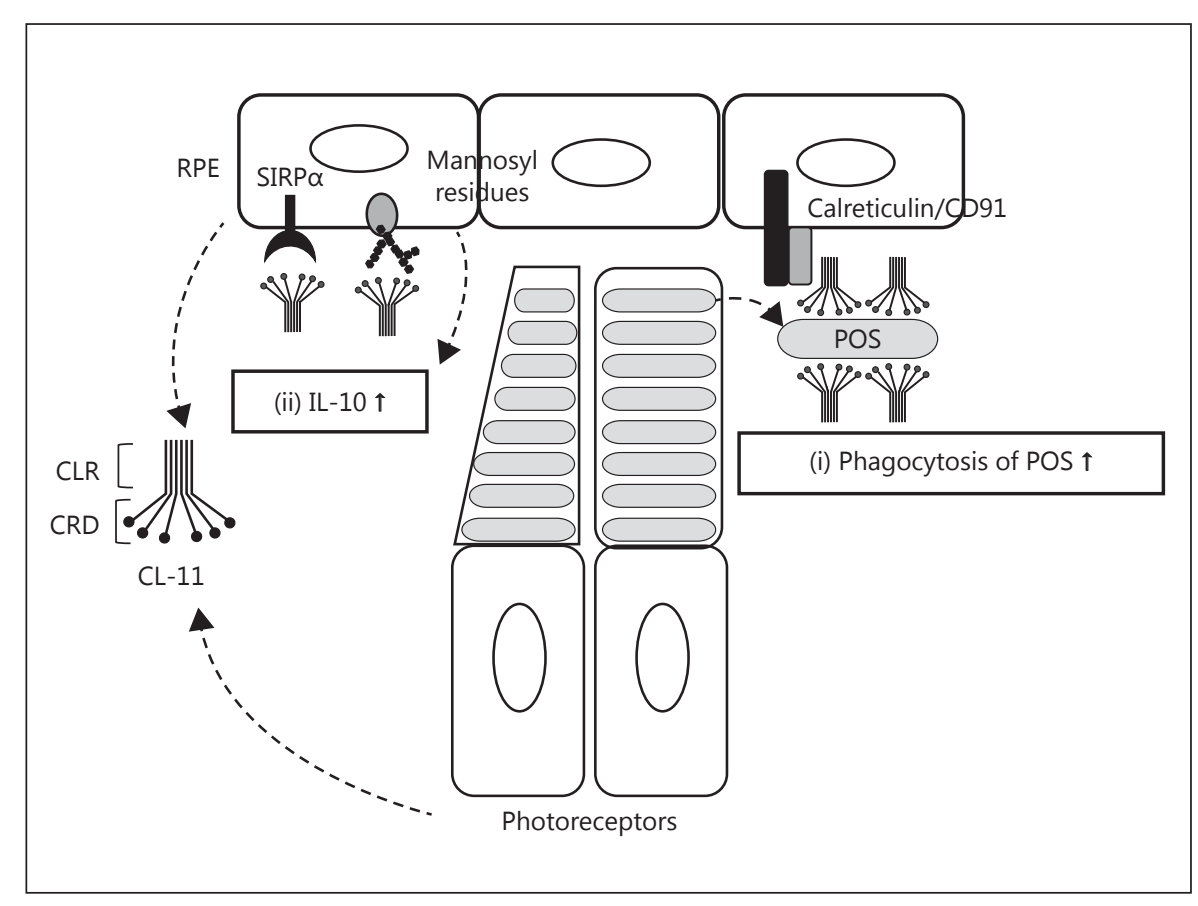

the involvement of calreticulin in CL-11-mediated opsonophagocytosis. Although our study did not address the binding structure of CL-11 to calreticulin, it has been shown that calreticulin is involved in the lung collectinmediated opsonophagocytosis of apoptotic cells by macrophages by interacting with their collagen-like region [21]. Thus, POS-bound CL-11 could interact with calreticulin on RPE cells through its collagen-like region to mediate the enhancement of phagocytosis of POS.

Cytokine production is another important function of RPE cells. The inflammatory microenvironment is thought to play an important role in immune homeostasis in the retina and in the pathogenesis of some retinopathies. Previous studies have shown that RPE cell cytokine production can be regulated by various stimuli such as inflammatory mediators (e.g., cytokines) [31] and biochemical patterns (e.g., N-retinylidene-N-retinylethanolamine) [32]. In this study, we showed that RPE cell cytokine production is differentially regulated by CL-11 (upregulation of IL-10 production and downregulation of IL-6 production), suggesting that CL-11 has anti-inflammatory effects on RPE cells. Furthermore, as such differential regulation was observed in both the normal culture condition and in the presence of additional inflammatory stimuli (IFN- $\gamma$ and LPS), CL-11-mediated regulation of cytokine production by RPE cells may have implications in both physiological and pathological conditions. When considering the molecule(s) responsible for the action of

Collectin-11 Modulates RPE Cell

Function
CL-11 on RPE cell production of cytokines, our study suggests that a specific type of sugar molecule (mannosyl residue) could be involved in CL-11-mediated modulation of cytokine production by RPE cells. This is supported by our findings that mannosyl residues and SIPR $\alpha$ are detected on RPE cells and that blocking the interaction of CL-11 with SIRPa (using anti-SIRPa) or removing mannosyl residues (using a-mannosidase) abrogates the effects of CL-11 on RPE cell cytokine production. Furthermore, our observations that CL-11 bound to mannosyl residues on the RPE cell surface and that removal of surface mannose reduced the CL-11 binding to RPE cells support the effect of CL-11 on cytokine production through binding of its CRD to mannosyl residues on RPE cells. Although the SIPRa molecular structure to which collectin binds is unknown (based on our current knowledge), it has been suggested that SIRPa is a highly glycosylated membrane protein, so maybe CL-11 binds to carbohydrate moieties on SIPRa to exert its effect. CL-11 has been reported to be able to trigger complement activation upon binding to pathogens or stress-induced L-fucose patterns [15-17]. Given that RPE cells can synthesize a number of complement components [33], the binding of CL-11 to RPE cells may cause complement activation, thus contributing to the effects of CL-11 on RPE cells that we observed in this study. However, this seems to not be the case in our culture system (online suppl. Fig. 3), as there was no indication of complement deposition on

J Innate Immun 2017;9:529-545 DOI: $10.1159 / 000478042$ 
RPE cells following CL-11 stimulation, though we cannot exclude the possibility in vivo.

CL-11 has relatively low serum concentrations (approx. $300 \mathrm{ng} / \mathrm{mL}$ ), compared to MBL (approx. $2 \mu \mathrm{g} / \mathrm{mL}$ ), and usually exists in the circulation as dimeric or trimeric forms $(>200 \mathrm{kDa})$ which may not be able to penetrate into the interstitial space of organs including the retina. This leads to the suggestion that locally produced CL-11 may play an important role in modulating parenchymal cell functions. In this study, we clearly demonstrated that CL11 is produced in the retina and RPE cells, and the small isoform seems to be more prominent. We also found that mannosyl residues are present on both POS and RPE, which are closely associated with CL-11 in the retina. Together, these findings strongly suggest that locally produced CL-11 can exert its biological functions through interacting with mannosyl residues on POS and RPE. Therefore, based on our in vitro and in vivo findings, we propose that CL-11 produced locally by RPE cells, and possibly by other cells, contributes to the CL-11 pool in the retina. Binding of CL-11 to phospholipid phosphatidylserine and mannosyl residues on shedded POS strengthens the contact of POS and RPE cells through the interaction of the CL-11 bound to POS and calreticulin on RPE cells, and this mediates or upregulates the phagocytosis of POS by RPE cells. In addition, the binding of CL11 to mannose-containing glycans and/or a specific glycoprotein (SIRP $\alpha$ ) on RPE cells mediates the upregulation of IL-10 production and the downregulation of IL- 6 production by the cells (Fig. 7). These regulations are critical for the clearance of shedded POS and the maintenance of immune homeostasis in the retina. Impairment of these regulations may have implications in retinal disease and disorders (e.g., age-related macular degeneration, diabetic retinopathy, and autoimmune retinopathy).

In conclusion, this study is the first to demonstrate that CL-11 plays a critical role in RPE cell phagocytosis and cytokine production, and it describes the molecular mechanisms involved in CL-11-mediated opsonophagocytosis and IL-10 production by RPE cells, thus opening new avenues for the study of the functional regulation of other phagocytic cells by CL-11 and the role of CL-11 in retinal health and disease.

\section{Acknowledgements}

This study was supported by the Medical Research Council, UK (G1001141 to W.Z.), the International Program for PhD Candidates of Sun Yat-sen University of China (to X.D.), the Major International Joint Research Project of the National Natural Science Foundation of China (No. 81320108008 to Y.L.). We thank Professor Russell Wallis for providing the FITC-labeled CL-11.

\section{Statement of Ethics}

The authors declare the use of normal mouse eye tissues was covered by our current project license, approved by the Home Office, UK. Obtaining the tissues adhered to the Animals (Scientific Procedures) Act of 1986, UK. The use of normal human eye tissues was approved by the Red Cross Eye Donation Society of Guangdong Province.

\section{Disclosure Statement}

The authors declare no commercial or financial conflicts of interest.

\section{Author Contributions}

X.D., W.W., L.M., C.L., L.W. and M.B.B. conducted experiments. W.Z. and K.L. designed the experiments. W.Z., K.L., X.D. and W.W. wrote the paper. E.F.N. prepared POS and helped designing phagocytosis experiments. E.F.N., H.X. and Y.L. helped reading and revising the paper.

\section{References}

1 Strauss O: The retinal pigment epithelium in visual function. Physiol Rev 2005;85:845-881.

2 Kevany BM, Palczewski K: Phagocytosis of retinal rod and cone photoreceptors. Physiology 2010;25:8-15.

3 Young RW, Bok D: Participation of the retinal pigment epithelium in the rod outer segment renewal process. J Cell Biol 1969;42:392-403.

4 Keshi H, Sakamoto T, Kawai T, Ohtani K, Katoh T, Jang SJ, Motomura W, Yoshizaki T, Fukuda M, Koyama S, Fukuzawa J, Fukuoh A,
Yoshida I, Suzuki Y, Wakamiya N: Identification and characterization of a novel human collectin CL-K1. Microbiol Immunol 2006; 50:1001-1013.

5 Ohtani K, Suzuki Y, Eda S, Kawai T, Kase T, Yamazaki H, Shimada T, Keshi H, Sakai Y, Fukuoh A, Sakamoto T, Wakamiya N: Molecular cloning of a novel human collectin from liver (CL-L1). J Biol Chem 1999;274:13681-13689.

6 Henriksen ML, Brandt J, Iyer SS, Thielens NM, Hansen S: Characterization of the inter- action between collectin 11 (CL-11, CL-K1) and nucleic acids. Mol Immunol 2013;56: 757-767.

7 Hansen SW, Ohtani K, Roy N, Wakamiya N: The collectins CL-L1, CL-K1 and CL-P1, and their roles in complement and innate immunity. Immunobiology 2016;221:1058-1067.

8 Holmskov U, Thiel S, Jensenius JC: Collections and ficolins: humoral lectins of the innate immune defense. Annu Rev Immunol 2003;21:547-578. 
9 Weis WI, Drickamer K, Hendrickson WA: Structure of a C-type mannose-binding protein complexed with an oligosaccharide. $\mathrm{Na}$ ture 1992;360:127-134.

10 Schwaeble W, Dahl MR, Thiel S, Stover C, Jensenius JC: The mannan-binding lectinassociated serine proteases (MASPs) and MAp19: four components of the lectin pathway activation complex encoded by two genes. Immunobiology 2002;205:455-466.

11 Kuhlman M, Joiner K, Ezekowitz RA: The human mannose-binding protein functions as an opsonin. J Exp Med 1989;169:1733-1745.

12 Ofek I, Mesika A, Kalina M, Keisari Y, Podschun R, Sahly H, Chang D, McGregor D, Crouch E: Surfactant protein D enhances phagocytosis and killing of unencapsulated phase variants of Klebsiella pneumoniae. Infect Immun 2001;69:24-33.

13 Selman L, Hansen S: Structure and function of collectin liver 1 (CL-L1) and collectin 11 (CL-11, CL-K1). Immunobiology 2012;217: 851-863.

14 Motomura W, Yoshizaki T, Ohtani K, Okumura T, Fukuda M, Fukuzawa J, Mori K, Jang SJ, Nomura N, Yoshida I, Suzuki Y, Kohgo Y, Wakamiya N: Immunolocalization of a novel collectin CL-K1 in murine tissues. J Histochem Cytochem 2008;56:243-252.

15 Farrar CA, Tran D, Li K, Wu W, Peng Q, Schwaeble W, Zhou W, Sacks SH: Collectin-11 detects stress-induced L-fucose pattern to trigger renal epithelial injury. J Clin Invest 2016;126:1911-1925.

16 Ma YJ, Skjoedt MO, Garred P: Collectin-11/ MASP complex formation triggers activation of the lectin complement pathway - the fifth lectin pathway initiation complex. J Innate Immun 2013;5:242-250.

17 Hwang I, Mori K, Ohtani K, Matsuda Y, Roy N, Kim Y, Suzuki Y, Wakamiya N: Collectin kidney 1 plays an important role in innate immunity against Streptococcus pneumoniae infection. J Innate Immun 2017;9:217-228.
18 Rooryck C, Diaz-Font A, Osborn DP, Chabchoub E, Hernandez-Hernandez V, Shamseldin H, Kenny J, Waters A, Jenkins D, Kaissi AA, Leal GF, Dallapiccola B, Carnevale F, Bitner-Glindzicz M, Lees M, Hennekam R, Stanier P, Burns AJ, Peeters H, Alkuraya FS, Beales PL: Mutations in lectin complement pathway genes COLEC11 and MASP1 cause 3MC syndrome. Nat Genet 2011;43:197-203.

19 Tang T, Li L, Tang J, Li Y, Lin WY, Martin F, Grant D, Solloway M, Parker L, Ye W, Forrest W, Ghilardi N, Oravecz T, Platt KA, Rice DS, Hansen GM, Abuin A, Eberhart DE, Godowski P, Holt KH, Peterson A, Zambrowicz BP, de Sauvage FJ: A mouse knockout library for secreted and transmembrane proteins. Nat Biotechnol 2010;28:749-755.

20 Mayerson PL, Hall MO, Clark V, Abrams T: An improved method for isolation and culture of rat retinal pigment epithelial cells. Invest Ophthalmol Vis Sci 1985;26:1599-1609.

21 Chen M, Muckersie E, Robertson M, Fraczek $\mathrm{M}$, Forrester JV, Xu H: Characterization of a spontaneous mouse retinal pigment epithelial cell line B6-RPE07. Invest Ophthalmol Vis Sci 2008;49:3699-3706.

22 Taylor PR, Carugati A, Fadok VA, Cook HT, Andrews M, Carroll MC, Savill JS, Henson PM, Botto M, Walport MJ: A hierarchical role for classical pathway complement proteins in the clearance of apoptotic cells in vivo. J Exp Med 2000;192:359-366.

23 Venkatraman Girija U, Furze CM, Gingras AR, Yoshizaki T, Ohtani K, Marshall JE, Wallis $\mathrm{AK}$, Schwaeble WJ, El-Mezgueldi $\mathrm{M}$, Mitchell DA, Moody PC, Wakamiya N, Wallis R: Molecular basis of sugar recognition by collectin-K1 and the effects of mutations associated with $3 \mathrm{MC}$ syndrome. BMC Biol 2015;13:27.

24 Barclay AN, Brown MH: The SIRP family of receptors and immune regulation. Nature Rev Immunol 2006;6:457-464.
25 Gardai SJ, Xiao YQ, Dickinson M, Nick JA, Voelker DR, Greene KE, Henson PM: By binding SIRPa or calreticulin/CD91, lung collectins act as dual function surveillance molecules to suppress or enhance inflammation. Cell 2003;115:13-23.

26 Law AL, Parinot C, Chatagnon J, Gravez B, Sahel JA, Bhattacharya SS, Nandrot EF: Cleavage of Mer tyrosine kinase (MerTK) from the cell surface contributes to the regulation of retinal phagocytosis. J Biol Chem 2015; 290:4941-4952.

27 Nandrot EF, Silva KE, Scelfo C, Finnemann SC: Retinal pigment epithelial cells use a MerTK-dependent mechanism to limit the phagocytic particle binding activity of $\alpha v \beta 5$ integrin. Biol Cell 2012;104:326-341.

28 Prasad D, Rothlin CV, Burrola P, BurstynCohen T, Lu Q, Garcia de Frutos P, Lemke G: TAM receptor function in the retinal pigment epithelium. Mol Cell Neurosci 2006;33:96108.

29 Ryeom SW, Silverstein RL, Scotto A, Sparrow JR: Binding of anionic phospholipids to retinal pigment epithelium may be mediated by the scavenger receptor CD36. J Biol Chem 1996;271:20536-20539.

30 Nandrot EF, Kim Y, Brodie SE, Huang X, Sheppard D, Finnemann SC: Loss of synchronized retinal phagocytosis and age-related blindness in mice lacking $\alpha v \beta 5$ integrin. J Exp Med 2004;200:1539-1545.

31 Holtkamp GM, Kijlstra A, Peek R, de Vos AF: Retinal pigment epithelium-immune system interactions: cytokine production and cytokine-induced changes. Prog Retin Eye Res 2001;20:29-48.

32 Anderson OA, Finkelstein A, Shima DT: A2E induces IL-1ss production in retinal pigment epithelial cells via the NLRP3 inflammasome. PLoS One 2013;8:e67263.

33 Fernandez-Godino R, Garland DL, Pierce EA: A local complement response by RPE causes early-stage macular degeneration. Hum Mol Genet 2015;24:5555-5569.
Collectin-11 Modulates RPE Cell

Function
J Innate Immun 2017;9:529-545

DOI: $10.1159 / 000478042$ 